\title{
Counting Complete? Finalising the plant inventory of a global biodiversity hotspot
}

\author{
Martina Treurnicht ${ }^{\text {Corresp., }}{ }^{1,2,3}$ ， Jonathan F Colville ${ }^{4,5}$ ， Lucas N Joppa $^{6}$ ， Onno Huyser ${ }^{7}$ ， John Manning ${ }^{8,9}$ \\ ${ }^{1}$ Conservation Ecology and Entomology, University of Stellenbosch, Stellenbosch, Western Cape, South Africa \\ 2 Institute of Landscape and Plant Ecology, University of Hohenheim, Stuttgart, Germany \\ 3 South African Environmental Observation Network Fynbos Node, Cape Town, Western Cape, South Africa \\ 4 Kirstenbosch Research Centre, South African National Biodiversity Institute, Cape Town, Western Cape, South Africa \\ 5 Statistics in Ecology, Environment and Conservation, Department of Statistical Sciences, University of Cape Town, Cape Town, Western Cape, South \\ Africa \\ 6 Microsoft Research, Redmond, WA, United States of America \\ 7 Centre for Biodiversity Conservation, Kirstenbosch Botanical Gardens, Table Mountain Fund (WWF-SA), Cape Town, Western Cape, South Africa \\ 8 Compton Herbarium, South African National Biodiversity Institute, Cape Town, Western Cape, South Africa \\ 9 Research Centre for Plant Growth and Development, University of KwaZulu-Natal, Pietermaritzburg, KwaZulu-Natal, South Africa \\ Corresponding Author: Martina Treurnicht \\ Email address: martinatreurnicht@gmail.com
}

The Cape Floristic Region - the world's smallest and third richest botanical hotspot - has benefited from sustained levels of taxonomic effort and exploration for almost three centuries, but how close is this to resulting in a near-complete plant species inventory? We analyse a core component of this flora over a 250-year period for trends in taxonomic effort and species discovery linked to ecological and conservation attributes. We show that $>40 \%$ of the current total of species was described within the first 100 years of exploration, followed by a continued steady rate of description. We propose that $<1 \%$ of the flora is still to be described. We document a relatively constant cohort of taxonomists, working over 250 years at what we interpret to be their 'taxonomic maximum'. Rates of description of new species were independent of plant growth-form but narrow-range taxa have constituted a significantly greater proportion of species discoveries since 1950 . This suggests that the fraction of undiscovered species predominantly comprises localised endemics that are thus of high conservation concern. Our analysis provides important realworld insights for other hotspots in the context of global strategic plans for biodiversity in informing considerations of the likely effort required in attaining set targets of comprehensive plant inventories. In a time of unprecedented biodiversity loss, we argue for a focused research agenda across disciplines to increase the rate of species descriptions in global biodiversity hotspots. 


\section{Counting Complete? Finalising the plant inventory of a global}

\section{2 biodiversity hotspot}

3

4 Martina Treurnicht ${ }^{1,2,3^{*}}$, Jonathan F. Colville ${ }^{4,5}$, Lucas N. Joppa ${ }^{6}$, Onno Huyser ${ }^{7}$ \& John

5 Manning 8,9

$7{ }^{1}$ Department of Conservation Ecology and Entomology, Stellenbosch University, Stellenbosch, 8 South Africa

$9{ }^{2}$ South African Environmental Observation Network Fynbos Node, Centre for Biodiversity 10 Conservation, Kirstenbosch Botanical Gardens, Cape Town, South Africa

$11{ }^{3}$ Institute of Landscape and Plant Ecology, University of Hohenheim, Stuttgart, Germany

$12{ }^{4}$ South African National Biodiversity Institute, Kirstenbosch Research Centre, Cape Town, South 13 Africa

145 Statistics in Ecology, Environment and Conservation, Department of Statistical Sciences, 15 University of Cape Town, Cape Town, South Africa

$16{ }^{6}$ Microsoft Research, 1 Microsoft Way, Redmond, WA 98075, U.S.A.

$17{ }^{7}$ Table Mountain Fund (WWF-SA), Centre for Biodiversity Conservation, Kirstenbosch Botanical 18 Gardens, Cape Town, South Africa

$19{ }^{8}$ Research Centre for Plant Growth and Development, School of Life Sciences, University of 20 KwaZulu-Natal, Pietermaritzburg, South Africa

$21{ }^{9}$ Compton Herbarium, South African National Biodiversity Institute, Cape Town, South Africa

$23 *$ Corresponding author

24 Martina Treurnicht; martinatreurnicht@gmail.com 


\section{Abstract}

27 The Cape Floristic Region - the world's smallest and third richest botanical hotspot - has benefited

28 from sustained levels of taxonomic effort and exploration for almost three centuries, but how close is this to resulting in a near-complete plant species inventory? We analyse a core component of this flora over a 250 -year period for trends in taxonomic effort and species discovery linked to ecological and conservation attributes. We show that $>40 \%$ of the current total of species was described within the first 100 years of exploration, followed by a continued steady rate of description. We propose that $<1 \%$ of the flora is still to be described. We document a relatively constant cohort of taxonomists, working over 250 years at what we interpret to be their 'taxonomic maximum'. Rates of description of new species were independent of plant growth-form but narrow-range taxa have constituted a significantly greater proportion of species discoveries since 1950. This suggests that the fraction of undiscovered species predominantly comprises localised endemics that are thus of high conservation concern. Our analysis provides important real-world insights for other hotspots in the context of global strategic plans for biodiversity in informing considerations of the likely effort required in attaining set targets of comprehensive plant inventories. In a time of unprecedented biodiversity loss, we argue for a focused research agenda across disciplines to increase the rate of species descriptions in global biodiversity hotspots. 


\section{Introduction}

44 Global biodiversity hotspots are species-rich areas of high conservation priority, including 45 significant numbers of rare and undiscovered species facing increasing threats of extinction (Myers et al., 2000; Giam \& Scheffers, 2012; Scheffers et al., 2012). They provide insight into ecological and evolutionary patterns associated with mega-diverse regions (Allsopp, Colville \& Verboom, 2014) and the taxonomic and conservation efforts required to document and manage this biodiversity (Cowling et al., 2003). Key to this is the urgent (Scheffers et al., 2012) but challenging (May, 2011) necessity for an adequate bio-inventory (Pimm et al., 2014).

Projections suggest that we are decades or more away from achieving acceptable bio-inventories for most hotspots and taxonomic groups (Mora et al., 2011). Compounding the uncertainty of how, when, or even if we will achieve this is the lack of adequate data on which to base realistic predictions. Most hotspots are historically under-resourced in terms of taxonomic and scientific effort (Cowling et al., 2010; Grieneisen et al., 2014), and are far short of achieving near-complete inventories for even conspicuous taxa such as flowering plants (Sobral \& Stehmann, 2009; Forzza requirement for assessing the time-span needed for a near-complete bio-inventory.

Recent analyses suggest that the majority of plant species still to be described are to be found within biodiversity hotspots (Sobral \& Stehmann, 2009; Joppa et al., 2011a). Although the rate at which species are documented is determined by taxonomic endeavour, the number of active taxonomists and their individual productivity varies greatly across different taxonomic groups 
65 (Joppa et al., 2011a; Bacher, 2012; Joppa, Roberts \& Pimm, 2012). No comparable analyses exist

66 for an entire flora. Analysing trends in species documentation over time for an entire floristic

67 hotspot will permit real-world predictions of the taxonomic effort required to describe the full

68 species complement of the hotspot. These can serve as guidelines for other species-rich areas in estimating the time frames required for meeting inventory targets such as the Convention on Biological Diversity targets for 2020 (http://www.cbd.int/gspc/targets.shtml). These estimates can guide the assessment of possible alternative conservation strategies that are less reliant on nearcomplete species inventories (Grantham et al., 2009; Cowling et al., 2010; Forest et al., 2015).

We focus here on the Cape Floristic Region (CFR, South Africa), one of the smallest (ca. 91000 $\mathrm{km}^{2}$ ) of the 25 biodiversity hotspots first identified by Myers et al. (2000), with a flora that is arguably one of the best known among the botanical hotspots. The CFR has been the subject of almost three centuries of intense botanical focus, with a current total of ca. 9400 recognised species of vascular plants and $>68 \%$ regional endemism (Manning \& Goldblatt, 2012). Due to its small size and long legacy of exploration and taxonomic effort, the inventory of vascular plants for the CFR appears to be effectively complete, although new species are still being discovered and described annually (Manning \& Goldblatt, 2012; SANBI, 2015). In this study, we analyse rates of plant species discovery and associated taxonomic effort in the CFR over a 250 year period (1753-2012), utilising techniques similar to those employed by Joppa, Roberts \& Pimm (2011b; 2011c). We apply these on a subset of $>2400$ 'Cape clade species' (sensu Linder, 2003), representing groups that are centred in the CFR and that also contain a disproportionally high number of endemic and threatened taxa (Raimondo et al., 2009). This allowed us to search for trends in species discovery and taxonomic activity in the study region. We also explored trends 
88 linked to abundance, ecology, and conservation status. Finally, we considered whether it is

89 possible to estimate how many 'missing species' (Solow \& Smith, 2005) remain in the CFR and

90 by what date we can expect to identify them.

\section{Materials and methods}

93 We analysed data for 2434 species selected from the 33 'Cape clades' identified by Linder (2003) 94 as "...those clades that have had most of their evolutionary history in the Cape Floristic Region" 95 (CFR; Table S1). These clades represent lineages for which we expect the highest rates of 96 description of new species in recent decades as a natural consequence of the high proportion of 97 local endemics and fire ephemerals in the CFR (Linder, 2003; Webb, Slik, \& Triono, 2010; 98 Manning \& Goldblatt, 2012). We restricted our selection within the clades to genera that (i) have been comprehensively and relatively recently monographed and (ii) included representatives from a wide spectrum of families and growth forms. Only currently accepted species as listed in Manning \& Goldblatt (2012) were accepted. Our selection comprises 55\% of Cape clade species and $26 \%$ of all vascular plant species recorded for the CFR.

We determined the date of publication of the protologue for each species, commencing with the publication of Species Plantarum (Linnaeus, 1753) and terminating with the publication of Cape Plants (Manning \& Goldblatt, 2012). Data on species habit and growth form were culled from Manning \& Goldblatt (2012) and from PRECIS (National Herbarium Pretoria Computerised Information System; Germishuizen et al., 2006). Species were classified as annuals, geophytes, graminoids, herbaceous perennials or shrubs. None of the species in the study group were trees.

110 Species distributions were summarised following the phytogeographic centres (sensu Brown \& 
111 Stuart, 2009) as given in Manning \& Goldblatt (2012). Species were considered to be 'local' if

112 present in a single phytogeographic centre and 'widespread' (or non-local) if present in more than 113 one phytogeographic centre.

114

115 We used sample scripts and functions, readily available online (from Joppa, Roberts \& Pimm, 116 2011b), to analyse trends in species discovery and taxonomic activity over ca. 250 years (1753117 2012). More specifically, we show "moving average functions" (sensu Joppa, Roberts \& Pimm, 118 2011b) described over five-year intervals for (i) the total number of species described, (ii) the 119 cumulative number of species, (iii) the number of taxonomists involved in describing species and 120 (iv) species described per taxonomist. The "number of taxonomists involved in describing species" 121 effectively represents the "taxonomic effort" whereas the measure "species per taxonomist" 122 represents the "catch" or "taxonomic efficiency" (sensu Joppa, Roberts \& Pimm, 2011b; Scheffers 123 et al., 2012). These measures split each unique taxonomic identity (often consisting of multiple 124 taxonomic authors) into individual taxonomic names and accounts for species described by more 125 than one taxonomic author. We then additionally show the (v) relative contribution of each 126 increment to the flora by dividing each accumulated five-year subtotal of the species described by 127 the cumulative total number of species described over the entire study period (i.e. proportion new 128 species (\%) described). Finally, we explore the cumulative number of species by ecological 129 attributes, i.e. (vi) growth form and (vii) phytogeographic centre (a proxy for abundance; from 130 Manning \& Goldblatt, 2012). All analyses were performed in R version 3.3.1 (R Development 131 Core Team, 2016). 
134 The number of vascular plant species described from the CFR for the 250 year period from 17531352012 has fluctuated widely over any given five-year increment, from a high of 106 species 136 described in 1830-1835 to a low of 9 species described during 1870-1875 (Fig. 1A; Table S2). 137 The post-World War II period (1945-1990) is characterised by a relatively steady rate in species 138 description of between 48 and 76 species per five-year increment (Fig. 1A; Table S2). Peaks in the 139 latter period represent the dates of publication of significant generic revisions or monographs (e.g. 140 Goldblatt, 1978; Bond \& Goldblatt, 1984; Linder, 2003). Overall, however, species in the sample 141 group were described at a remarkably consistent rate over the entire study period (Fig. 1B), with 142 at most only a very slight positive trend in number of species described $(x=46.51 \pm 20.03)$ per 143 increment.

145 The number of publishing taxonomists per increment ranged from 2 to 17 with a very slight trend 146 towards more taxonomists over time (Fig. 1C; Table S2), balanced by a corresponding decline in 147 the number of species published per taxonomist (Fig. 1D; Table S2).

Naturally (from Fig. 1A,B), the number of new species described each half decade represents a diminishing proportion of the total number of species described over the entire period (Fig. 1E) but the relationship is strongly logarithmic, with a large proportion (41\%) of species described within the first century of taxonomic study (1753-1850). Thereafter the additional species contributions stabilised at a modest incremental increase of $3 \%$ for the period $1850-1985$, with a

154 further decline to the current level of 1.36\% (1990-2012; Table S2). 
156 Rates of description of species remained relatively consistent from 1753-2012 regardless of

157 growth form (Fig. 1F), with shrubby species described at a higher rate than other growth forms. In

158 contrast, analysis of the cumulative species by species distribution reveals a critical difference

159 between local and widespread (or non-local) species (Fig. 1G). Local and non-local species

160 accumulated at comparable rates over the period 1753-1930, with a consistently greater number

161 of widespread species being named. The period after 1950, however, documents a deceleration in

162 the description of non-local taxa and a marked acceleration in the description of local taxa. From

1631950 onwards, the number of local taxa described per half decade exceeds the number of

164 widespread taxa described in the same period, with a widening difference between the two trends

165 (Fig. 1G).

166

167 Discussion

168 Our study shows that there has been a sustained level of taxonomic interest in the CFR over more 169 than 250 years of active botanical study. Species have been described at a constant rate over this

170 entire period, reflecting a sustained level of taxonomic output by a relatively stable number of

171 active taxonomists (Fig. 1C,D). From this, we conclude that there is a finite number of species that

172 can be processed by any taxonomist over a fixed period in their working life. Specifically, we

173 suggest that there is a maximum limit to the 'productivity' of any taxonomist, a measure that we

174 term here the 'taxonomic maximum', determined by several factors (e.g. taxonomic group,

175 personality, institutional support, etc.). On the assumption that botanical study in the CFR has

176 proceeded at or near the taxonomic maximum (Fig. 1), we conclude that it is unreasonable to

177 expect an increase in individual taxonomic output under current technologies. The operational

178 concepts applied by practising taxonomists, although seldom if ever explicitly outlined, may also 
179 influence a taxonomist's output. We can accept, however, that the species concepts applied by

180 taxonomists in this study are essentially morphological, sometimes in concert with ecological

181 considerations, and there seems little doubt that this is overwhelmingly the case elsewhere in

182 megadiverse regions.

183

184 The CFR has been the subject of botanical exploration since the fifteenth century, with a period of 185 particular intensive discovery and documentation in the late eighteenth century (Glen \& 186 Germishuizen, 2010). This early knowledge was consolidated and expanded in the nineteenth 187 century in the publication of the Flora capensis (Harvey, Sonder \& Thiselton-Dyer, 1869-1900). 188 Taxonomic activity over this period, based on typological principles and practised largely by non189 resident scientists from foreign institutes in Britain and Europe, resulted primarily in a proliferation 190 of names. The early part of the twentieth century was a period of more intensive study associated 191 with the establishment of the region's two primary taxonomic institutes, the University of Cape 192 Town and Kirstenbosch Botanical Garden, with a resident staff. Botanists at these institutes studied 193 the local flora in the herbarium and in the field, and also encouraged collecting among local 194 amateurs. Current civil society programmes continue this valuable contribution in the CFR 195 (SANBI, 2015). Similar investments have also made valuable contributions to species discoveries 196 in other hotspots (e.g. the Southwest Australian Floristic Region (SWAFR; Hopper \& Gioia, 197 2004)). It should not be overlooked that the actual taxonomic effort expended in the early twentieth 198 century is obscured in our analyses by the fact that we have not included the number of names that 199 disappeared into synonymy during each half decade. This is a significant part of the effort 200 necessary for an accurate bio-inventory. 
202 Professional taxonomists remain the critical resource and our findings suggest that the most

203 effective way of increasing 'taxonomic effort', and thus the rate at which any flora is catalogued,

204 is by increasing the number of active taxonomists (e.g. Godfray, 2002; Bacher, 2012). Our analysis

205 of the activity of taxonomists also reflects a trend towards multi-authored species, as discerned by

206 Joppa, Roberts \& Pimm (2011b).

207

208 The proportionally higher number of shrubby species in our study group reflects the predominance 209 of this habit (54\% of the flora) in the CFR study region (Goldblatt \& Manning, 2002; Linder, 210 2003). Other categories are also broadly consistent with their representation in the flora as a whole

211 but reflect sampling bias in the study group (notably graminoids, which are overrepresented in the 212 sample).

214 The documentation of the CFR flora has proceeded as a logarithmic function, with a long tail 215 representing an incremental addition to the floristic inventory of $1-5 \%$ of the sample group every 216 five years. It is an astonishing finding that the description of species from the CFR has continued 217 at essentially the same rate since the documentation of the flora started over 250 years ago. In 218 essence, therefore, the number of newly described species appears to continue to increase at a rate 219 of 20-60 species every five years. Effectively, however, the 'missing species' thus comprise an 220 insignificant proportion of those already described. Based on the fact that some half of the CFR 221 species are members of the Cape clades used to generate these trends, we estimate that the "missing 222 species' remaining in the CFR constitute $<1 \%$ of the total flora, which falls far below the predicted 223 numbers of missing plant species (ca. 15\%) for other hotspots (Joppa, Roberts \& Pimm, 2011c; 224 see also Webb, Slik, \& Triono, 2010; Laurance \& Edwards, 2011; Scheffers et al., 2012). For most 
225 practical purposes, therefore, the botanical diversity in the CFR can be considered to be adequately

226 known. Critically, however, the 'missing species' in the CFR are likely to be range-restricted, local

227 endemics that are thus especially vulnerable to extinction (e.g. Fig. 1G).

228

229

The Cape flora is characterised by high numbers of local endemics, reflected in the high levels of beta and gamma diversity across the region (Cowling, Holmes \& Rebelo, 1992; Goldblatt \& Manning, 2000). As we might expect, the distinction between local and more widespread species appears to be the primary determinant of the likelihood of discovering new species in the CFR since 1950. This conclusion is universal to global biodiversity hotspots (Scheffers et al., 2012).

The number of local endemics in the CFR described in the past 50 years is high enough to offset the declining rate at which more widespread taxa are being discovered. This finding has significant implications for conservation in the CFR, and likely also other global hotspots, by confirming that locally endemic taxa are among the last to be discovered. This increases the risk that they will be driven to extinction before being documented since the transformation of species-rich natural habitats continues at alarming rates in both Mediterranean- and tropical hotspots (e.g. Giam \& taxonomic effort and to increase the level of exploration of these hotspots.

The species accumulation trends that we have documented here demonstrate that the CFR is in an enviable position among global biodiversity hotspots in that its botanical diversity is now effectively documented. We are only able to reach this conclusion because the region has been extensively and intensively studied over a period of almost three centuries with a relatively 
248 constant taxonomic effort. The situation in other hotspots and among other taxonomic groups (e.g.

249 Picker, Colville \& Van Noort, 2002) is seldom so favourable. The development of comprehensive 250 conservation assessments of individual species (e.g. Raimondo et al., 2009) as a guide to decision-

251 making on how best to invest scarce conservation resources is only possible once near-complete

252 species inventories exist. Such inventories depend on a combination of exploration and 253 documentation. The first objective of the GSPC is to ensure that "plant diversity is well understood, 254 documented and recognised" (GSPC, https://www.cbd.int/gspc/objectives.shtml) and our CFR 255 case study directly illustrates that obtaining such a basis for biodiversity estimates takes both time 256 and taxonomic investment. Similar investigations are needed in other Mediterranean hotspots (e.g. 257 SWAFR, California) that have experienced extensive botanical exploration to allow comparative 258 estimates on plant inventories among these hotspots and thus contribute to the foundational 259 objective of the GSPC.

261 Even if most plant species in the CFR have been named, we largely lack information on abundance, 262 distribution, ecology and other attributes of species that affect their conservation (e.g. Raimondo 263 et al., 2009; Costello, Vanhoorne, \& Appeltans, 2015). Recent national threatened species 264 programmes, local citizen science projects, and modern taxonomic revisions have contributed 265 significantly to both species discoveries and unknown locality records of species in the CFR (e.g. 266 Raimondo et al., 2009; Manning \& Goldblatt, 2012; SANBI, 2015). Maintaining or even 267 increasing the funding that supports such collaborative efforts is urgent, especially in regions that 268 may not have a long legacy of botanical exploration. Key to filling these gaps in global biodiversity 269 hotspots is thus to increase collaboration amongst international taxonomists, maintain current 270 taxonomic effort, and increase expertise by including non-specialists (Costello, Vanhoorne, \& 
271 Appeltans, 2015), so as to shrink 'the pool of missing species' (sensu Joppa et al. 2011b).

272 Disproportionately many undiscovered species in hotspots may remain as cryptic endemics with 273 complex morphological differentiation, requiring a combination of specialist taxonomic input,

274 trained technicians and novel techniques (e.g. Ficetola et al., 2008) across disciplines (taxonomy, 275 systematics, molecular phylogenetics, population genetics, and ecology; Webb, Slik \& Triono, 276 2010; Scheffers et al., 2012). The CFR case study we have presented here provides a valuable but 277 rare real-world dataset that other biodiversity hotspots can use to estimate the resources in time, 278 effort, taxonomic output and potential alternative strategies that would be needed to achieve 279 adequate documentation of plant species.

\section{Acknowledgements}

283 We are grateful to Domitilla Raimondo, Lize Von Staden (Threatened Species Programme, South African National Biodiversity Institute (SANBI)) and Ismail Ebrahim (SANBI) for insightful discussions; Ilva Rogers and Les Powrie (SANBI) for assistance with data.

\section{Supplemental Information}

Supplemental information for this article can be found online.

\section{References}

Allsopp N, Colville JF, Verboom GA. 2014. Fynbos: Ecology, Evolution, and Conservation of a Megadiverse Region. Oxford: Oxford University Press. 
293

Bacher S. 2012. Still not enough taxonomists: reply to Joppa et al. Trends in Ecology \& Evolution 27:65-66.

Bond P, Goldblatt P. 1984. Plants of the Cape flora. Journal of South African Botany 13:Suppl. Cape Town.

Brown RM, Stuart BL. 2009. Patterns of biodiversity discovery through time: an historical analysis of amphibian species discoveries in the Southeast Asian mainland and adjacent island archipelagos. In: Gower DJ, Johnson KG, Richardson JE, Rosen BR, Rüber L, Williams ST, eds. Biotic evolution and environmental change in Southeast Asia. Cambridge: Cambridge University Press, 348-389.

Cowling RM, Holmes PM, Rebelo AG. 1992. Plant diversity and endemism. In: Cowling RM, ed. The ecology of fynbos: nutrients, fire and diversity. Cape Town, Oxford University Press, 62112.

Cowling RM, Knight AT, Privett SDJ, Sharma G. 2010. Invest in opportunity, not inventory of hotspots. Conservation Biology 24:633-635.

Cowling RM, Pressey RL, Rouget M, Lombard AT. 2003. A conservation plan for a global biodiversity hotspot - The Cape Floristic Region, South Africa. Biological Conservation 112:191-216.

Costello MJ, Vanhoorne B, Appeltans W. 2015. Conservation of biodiversity through taxonomy, data publication, and collaborative infrastructures. Conservation Biology 29(4):1094-1099.

Ficetola GF, Miaud C, Pompanon F, Taberlet P. 2008 Species detection using environmental DNA from water samples. Biology Letters 4:423-425.

Forest F, Crandall KA, Chase MW, Faith DP. 2015. Phylogeny, extinction and conservation: embracing uncertainties in a time of urgency. Philosophical Transactions of the Royal Society of London B: Biological Sciences 370:1-8.

Forzza R, Baumgratz J. 2012. New Brazilian floristic list highlights conservation challenges. Bioscience 62:39-45.

Germishuizen G, Meyer NL, Steenkamp Y, Keith M. 2006. Checklist of South African Plants. Southern African Botanical Diversity Network Report No. 41. Pretoria: Sabonet. 
321 Giam X, Scheffers B. 2012. Reservoirs of richness: least disturbed tropical forests are centres of 322 undescribed species diversity. Proceedings of the Royal Society of London B: Biological Sciences 279:67-76.

324 325

326

327

328

329

330

331

332

333

334

335

336

337

338

339

340

341

342

343

344

345

346

347

Glen HF, Germishuizen G. 2010. Botanical exploration, $2^{\text {nd }}$ edn. Strelitzia 26. South African National Biodiversity Institute, Pretoria.

Godfray HCJ. 2002. Challenges for taxonomy. Nature 417:17-19.

Goldblatt P. 1978. An analysis of the flora of Southern Africa: its characteristics, relationships, and origins. Annals of the Missouri Botanical Garden 65:369-436.

Goldblatt P, Manning J. 2000. Cape Plants: a conspectus of the Cape flora of South Africa. Strelitzia 9. Pretoria: National Botanical Institute of South Africa.

Goldblatt P, Manning JC. 2002. Plant Diversity of the Cape Region of Southern Africa. Annals of the Missouri Botanical Garden 89:281-302.

Grantham HS, Wilson KA, Moilanen A, Rebelo T, Possingham HP. 2009. Delaying conservation actions for improved knowledge: how long should we wait? Ecology Letters 12:293-301.

Grieneisen ML, Zhan Y, Potter D, Zhang M. 2014. Biodiversity, Taxonomic Infrastructure, International Collaboration and New Species Discovery. Bioscience 64:322-332.

Harvey WH, Sonder OW, Thiselton-Dyer WT. 1869-1900. Flora capensis: being a systematic description of the plants of the Cape colony, Caffraria, \& Port Natal (and neighbouring territories) v. 1-7. Kent.

Hopper SD, Gioia P. 2004. The southwest Australian floristic region: evolution and conservation of a global hot spot of biodiversity. Annual Review of Ecology, Evolution and Systematics 35: $623-650$.

Joppa LN, Roberts DL, Myers N, Pimm SL (2011a) Biodiversity hotspots house most undiscovered plant species. Proceedings of the National Academy of Sciences 108:1317113176.

Joppa LN, Roberts DL, Pimm SL. 2011b. The population ecology and social behaviour of taxonomists. Trends in Ecology \& Evolution 26:551-553. 
348 Joppa LN, Roberts DL, Pimm SL. 2011c. How many species of flowering plants are there? Proceedings of the Royal Society B: Biological Sciences 278:554-9.

350

Joppa LN, Roberts DL, Pimm SL. 2012. Taxonomy that matters: response to Bacher. Trends in Ecology \& Evolution 27:66.

Linnaeus C. 1753. Species Plantarum Exhibitentes Plantas Rite Cognitas ad Genera Relatas, cum Differentiis Specificis, Nominibus Trivialibus, Synonymis Selectis, et Locis Natalibus, Secundum Systema Sexuale Digestas, ed. 1. Laurentius Salvius, Stockholm, Sweden. Facsimile published 1957-1959 as Ray Soc. Publ. 140 and 142. London: The Ray Society.

Laurance WF, Edwards DP. 2011. The search for unknown biodiversity. Proceedings of the National Academy of Sciences 108:12971-12972.

Linder HP. 2003. The radiation of the Cape flora, southern Africa. Biological Reviews 78:597638.

Manning J, Goldblatt P. 2012. Plants of the Greater Cape Floristic Region 1: the Core Cape Flora. Strelitzia 29. Pretoria: South African National Biodiversity Institute.

May RM. 2011. Why worry about how many species and their loss? PLoS Biology 9:1-2.

Mora C, Tittensor DP, Adl S, Simpson AGB, Worm B. 2011. How many species are there on earth and in the ocean? PLoS Biology 9:1-8.

Myers N, Mittermeier RA, Fonseca GAB, Fonseca GAB, Kent J. 2000. Biodiversity hotspots for conservation priorities. Nature 403:853-8.

Picker M, Colville J, Van Noort S. 2002. Mantophasmatodea now in South Africa. Science 297: 1475 .

Pimm SL, Jenkins CN, Abell R, Brooks TM, Gittleman JL, Joppa LN, Raven PH, Roberts CM, Sexton JO. 2014. The biodiversity of species and their rates of extinction, distribution, and protection. Science 344:1246752.

R Development Core Team. 2016. R: A language and environment for statistical computing. R Foundation for Statistical Computing, Vienna, Austria. 
374 Raimondo D, Von Staden L, Foden W, Victor JE, Helme NA, Turner RC, Kamundi DA, Manyama 375 PA. 2009. Red List of South African Plants. Strelitzia 25. Pretoria: South African National $376 \quad$ Biodiversity Institute.

377 SANBI 2015. Statistics: Red List of South African Plants version 2015.1. Downloaded from $378 \quad$ Redlist.sanbi.org on 2016/10/29.

379 Scheffers BR, Joppa LN, Pimm SL, Laurance WF. 2012. What we know and don't know about $380 \quad$ Earth's missing biodiversity. Trends in Ecology \& Evolution 27:501-510.

381 Sobral M., Stehmann JR. 2009. An analysis of new angiosperm species discoveries in Brazil 382 (1990-2006). Taxon 58:227-232.

383 Solow AR, Smith WK. 2005. On estimating the number of species from the discovery record. 384 Proceedings of the Royal Society of London B: Biological Sciences 272:285-287.

385 Webb CO, Slik JWF, Triono T. 2010. Biodiversity inventory and informatics in Southeast Asia. $386 \quad$ Biodiversity and Conservation 19:955-972 


\section{$387 \quad$ Figures}

388 Figure 1. Trends over time (1753-2012) in species discovery rates and taxonomic effort in the

389 Cape Floristic Region, South Africa: (A) Total number of species described, (B) cumulative

390 number of species, (C) number of taxonomists involved in describing species ("taxonomic effort")

391 and (D) species described per taxonomist ("taxonomic efficiency"). Plotted lines are moving

392 average functions (sensu Joppa, Roberts \& Pimm, 2011b) calculated at five-year time intervals

393 across the study period (i.e. 1753-2012). (E) The proportion (\%) of new species described per

394 five-year interval, (F) cumulative number of species per growth form (annual [19], geophyte [289],

395 graminoid [520], herbaceous perennial [19] and shrub [1587]) and (G) phytogeographic centre

396 (widespread and local; see main text for details) across the study period. Trend lines (dashed black)

397 in A,C,D are based on linear model fits whereas the trend line in E is based on a mean rate of 8.98

398 species described. 

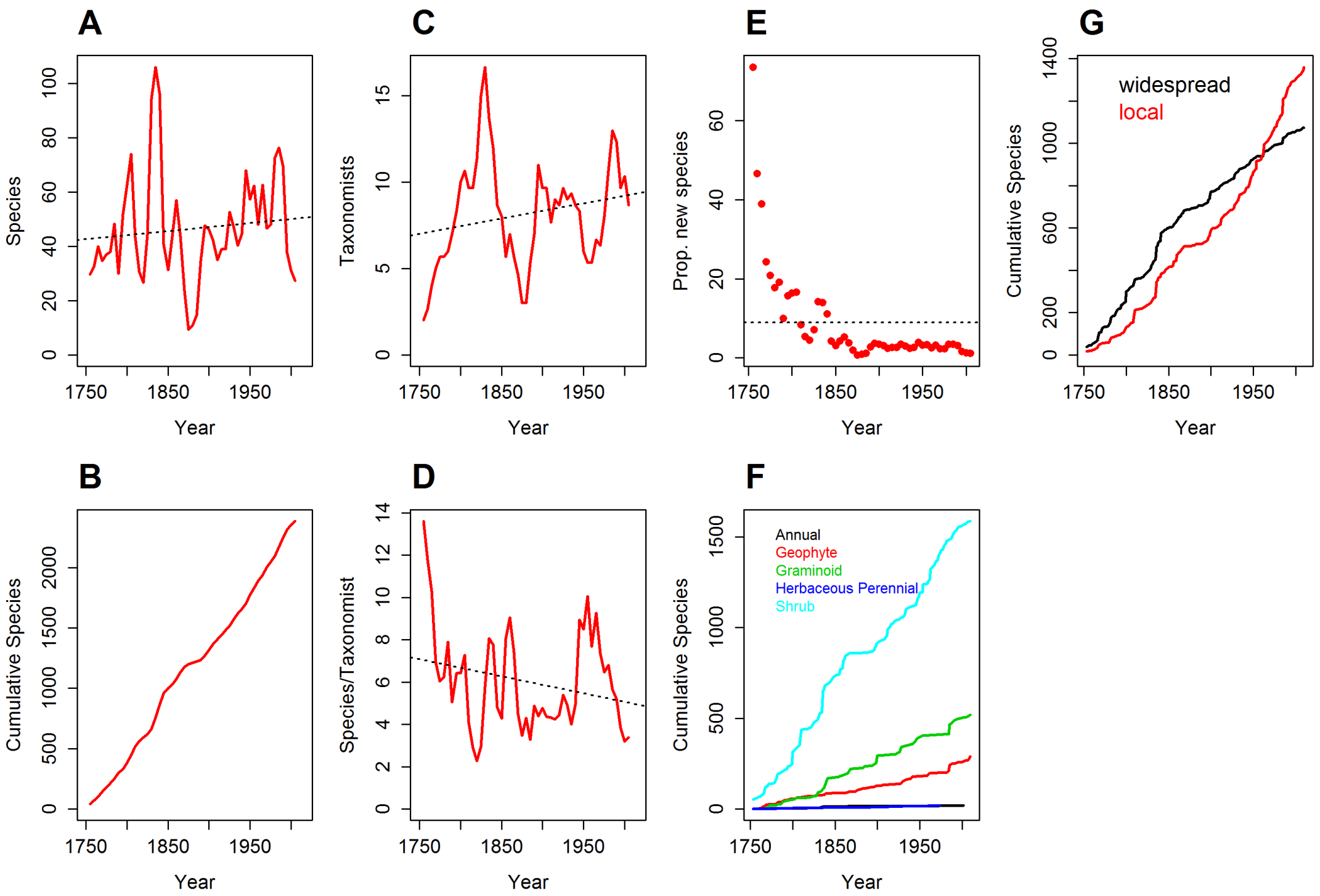

400 Figure 1. 